06,13

\title{
Слабое проявление эффекта поля в структурах металл-диэлектрик-полупроводник с сегнетоэлектрическим изолирующим слоем $\mathrm{Ba}_{x} \mathrm{Sr}_{1-x} \mathrm{TiO}_{3}$
}

\author{
(С) Д.А. Белорусов, Е.И. Гольдман, Г.В. Чучева \\ Фрязинский филиал Института радиотехники и электроники им. В.А. Котельникова РАН, \\ Фрязино, Московская обл., Россия \\ `E-mail: gvc@ms.ire.rssi.ru
}

Поступила в Редакцию 29 июня 2021 г.

В окончательной редакции 29 июня 2021 г.

Принята к публикации 3 июля 2021 г.

Проведены высокочастотные измерения емкости и проводимости объектов $\mathrm{Ni}-\mathrm{Ba}_{0.8} \mathrm{Sr}_{0.2} \mathrm{TiO}_{3}-\mathrm{Pt}$ и $\mathrm{Ni}-\mathrm{Ba}_{0.8} \mathrm{Sr}_{0.2} \mathrm{TiO}_{3}-\mathrm{Si}$ с толщиной сегнетоэлектрика $120 \mathrm{~nm}$ в параэлектрической фазе. Показано, что во всем диапазоне внешних напряжений электрическое поле в $\mathrm{Si}$ практически не проникает. Подтвержден сделанный ранее вывод о причинах слабого проявления эффекта поля - происходит практически полное экранирование поляризации сегнетоэлектрического слоя зарядами электронных ловушек на контакте $\mathrm{Ba}_{0.8} \mathrm{Sr}_{0.2} \mathrm{TiO}_{3}-\mathrm{Si}$. Отмечено, что резкое снижение за счет пассивации активности поверхностных ловушек позволит реализовать транзисторы на базе структур металл-BST-Si с работающим поверхностным каналом неосновных носителей заряда и обеспечит построение высококачественных ячеек энергонезависимой памяти FeRAM.

Ключевые слова: металл-диэлектрик-полупроводник-структуры, металл-диэлектрик-металл-структуры, сегнетоэлектрические пленки состава $\mathrm{Ba}_{0.8} \mathrm{Sr}_{0.2} \mathrm{TiO}_{3}$, высокочастотный импеданс.

DOI: 10.21883/FTT.2021.11.51592.154

\section{1. Введение}

Сегнетоэлектрические пленки - это одна из приоритетных альтернатив изолирующим слоям окисла кремния для использования в электронных устройствах. [1]. Уникальные физические свойства сегнетоэлектрических материалов (в частности, высокая и изменяемая под действием внешнего электрического поля диэлектрическая проницаемость) позволяют создавать на основе планарной технологии фактически новые классы устройств хранения и обработки информации [2]. Твердые растворы титаната бария-стронция $\left(\mathrm{Ba}_{1-x} \mathrm{Sr}_{x} \mathrm{TiO}_{3}\right.$ или BST) обладают сегнетоэлектрическими свойствами выше комнатной температуры, а их диэлектрическая постоянная остается достаточно высокой и в параэлектрической фазе. Но, хотя исследования пленок BST начались с конца прошлого века $[3,4]$, до сих пор нет сообщений о транзисторных структурах на базе этих сегнетоэлектриков с работающими проводящими поверхностными каналами неосновных носителей заряда в полупроводнике нанометрового диапазона [5]. В опытах [6] на структурах Ni-BST-Si с толщиной сегнетоэлектрической пленки $h=350 \mathrm{~nm}$ и составом $\mathrm{Ba}_{0.8} \mathrm{Sr}_{0.2} \mathrm{TiO}_{3}$ была обнаружена возможная причина слабого проявления эффекта поля - практически полное экранирование поляризации сегнетоэлектрического промежутка зарядами электронных ловушек в межфазном слое на контакте с кремнием. Это важный результат, поскольку известные из кремниевой планарной технологии способы пассивации ловушек в межфазном слое позволяют надеяться на устранение препятствий для открытия канала проводимости неосновных носителей заряда в полупроводнике и тем самым обеспечить перспективу для создания ячеек энергонезависимой памяти FeRAM на базе структур c BST. Для развития работ в этом направлении важна уверенность в общности сделанных в [6] выводов в отношении структур с разными толщинами сегнетоэлектрика, нанесенного на подложки $n$ - и $p$-типов. С целью такой проверки результатов [6] в настоящей работе приведены результаты исследований образцов Ni-BST-Si и Ni-BST-Pt с более тонким слоем сегнетоэлектрика $h=120 \mathrm{~nm}$.

\section{2. Высокочастотный импеданс структур $\mathrm{Ni}-\mathrm{Ba}_{0.8} \mathrm{Sr}_{0.2} \mathrm{TiO}_{3}-\mathrm{Si}$ и $\mathrm{Ni}-\mathrm{Ba}_{0.8} \mathrm{Sr}_{0.2} \mathrm{TiO}_{3}-\mathrm{Pt}$}

В работе [6] была развита одномерная модель высокочастотного (ВЧ) импеданса структур металл-сегнетоэлектрик-полупроводник с буферным слоем на контакте с подложкой. Анализ на базе развитой модели экспериментальных характеристик подобных структур и образцов металл-сегнетоэлектрик-металл позволяет определить в зависимости от внешнего напряжения изгиб зон в полупроводнике и концентрацию заряда в буферном слое между BST и Si. Строго говоря, данная модель применима в параэлектрической фазе изолирующего слоя. Поэтому измерения ВЧ-характеристик 
нужно проводить при температурах существенно выше комнатной.

Экспериментальные исследования были выполнены на структурах Ni-BST-Pt и Ni-BST-Si с площадью $S=2.7 \cdot 10^{-4} \mathrm{~cm}^{2}$. В качестве подложек использовался тот же, что и в [6], кремний $n$-типа, $N_{d}=2.4 \cdot 10^{14} \mathrm{~cm}^{-3}$ с подслоем платины, либо естественным окислом на поверхности пластины. Сегнетоэлектрическую пленку толщиной $h=120 \mathrm{~nm}$ наносили методом высокочастотного распыления поликристаллической мишени в атмосфере кислорода на установке Плазма-50СЭ (Россия). Более детально конструкции установок и методика осаждения пленок описаны в $[7,8]$. Измерения импеданса проводились в параэлектрической фазе в области температур $110-130^{\circ} \mathrm{C}$ на той же частоте $1 \mathrm{MHz}$, что и в [6], с использованием прецизионного измерителя LCR Agilent E4980A, портативного компьютера с доработанным программным обеспечением и специальной камеры, снабженной нагревательным столиком с термостабилизацией. Подробности экспериментальной установки описаны в [9].

Результаты опытов представлены на рис. 1 и 2 для температуры измерений $121^{\circ} \mathrm{C}$.

Формы кривых для других температур были близки к показанным на данных рисунках. Как и у образцов из работы [6], имеют место неравенства $(G / \omega C) \propto(1 / 100) \ll 1,\left(C_{S E} / C\right) \propto 10 \div 100 \gg 1$, где $C$ и $G$ - емкость и проводимость структур Ni-BST-Si, $C_{S E}$ - емкость образца Ni-BST-Pt, $\omega$ - циклическая частота измерений импеданса. Из модели ВЧимпеданса $[6$, формула (5)] следует неравенство

$$
\begin{aligned}
1 \gg & \frac{C}{\omega C}>\left\{\left[1-\frac{\left(C+\frac{G^{2}}{\omega^{2} C}\right)}{C_{S}}\right]\right. \\
& \left.\times\left[\frac{\left(C+\frac{G^{2}}{\omega^{2} C}\right)}{C_{S E}}+\frac{\left(C+\frac{G^{2}}{\omega^{2} C}\right)}{C_{S}}-1\right]\right\}^{1 / 2} .
\end{aligned}
$$

Здесь $C_{s}$ - емкость граничащей с BST заряженной области кремния. Поэтому для наших образцов, как и в опытах [6], для всей области подаваемых напряжений получается

$$
C \cong C_{s} .
$$

Таким образом, табулируя зависимость $C_{s}$ от изгиба зон в полупроводнике $V_{s}$ по выражениям для классической статистики [10]:

$$
C_{s}=\frac{C_{s f b}}{2^{(1 / 2)}} \frac{\left|1-e^{-v_{s}}\right|}{\left(e^{-v_{s}}+v_{s}-1\right)^{(1 / 2)}}, v_{s}=-\frac{q V_{s}}{T},
$$

можно через цепочку взаимосвязей $V_{g} \Rightarrow C=C_{s} \Rightarrow$ $v_{s} \Rightarrow V_{s}$ построить зависимость изгиба зон от внешнего напряжения $V_{g}$. Здесь $C_{s f b}-$ емкость полупроводника в состоянии flat band $\left(V_{s}=0\right) ; v_{s}=-\frac{q V_{s}}{T}-$ безразмерный изгиб зон в полупроводнике, $v_{s}>0$ при обеднении поверхности кремния; $q$ - элементарный заряд; $T$ -

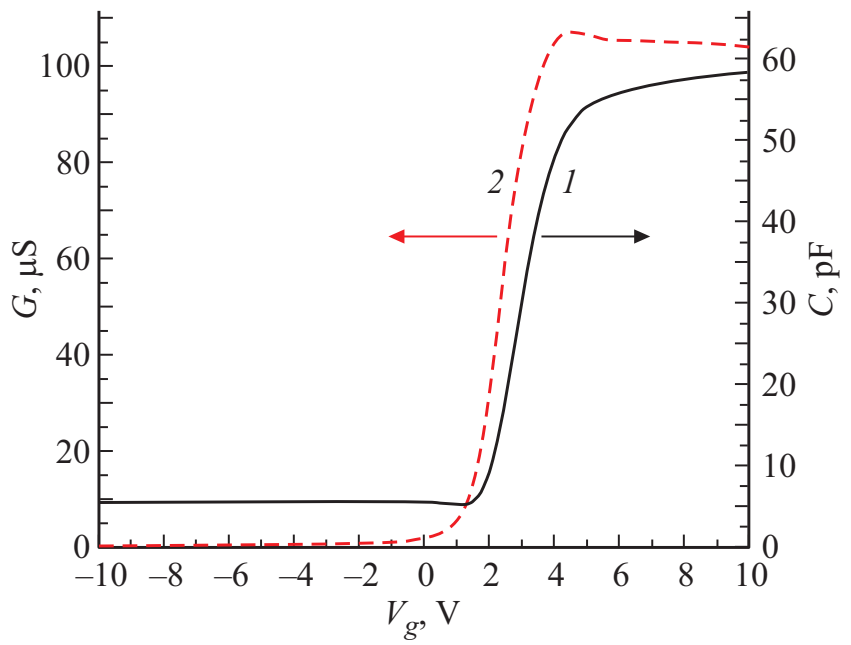

Рис. 1. Высокочастотные полевые характеристики структуры $\mathrm{Ni}-\mathrm{Ba}_{0.8} \mathrm{Sr}_{0.2} \mathrm{TiO}_{3}-\mathrm{Si}$ с толщиной сегнетоэлектрика $120 \mathrm{~nm}$, измеренные при $T=121^{\circ} \mathrm{C}$. Кривые: $1-$ емкость, 2 проводимость.

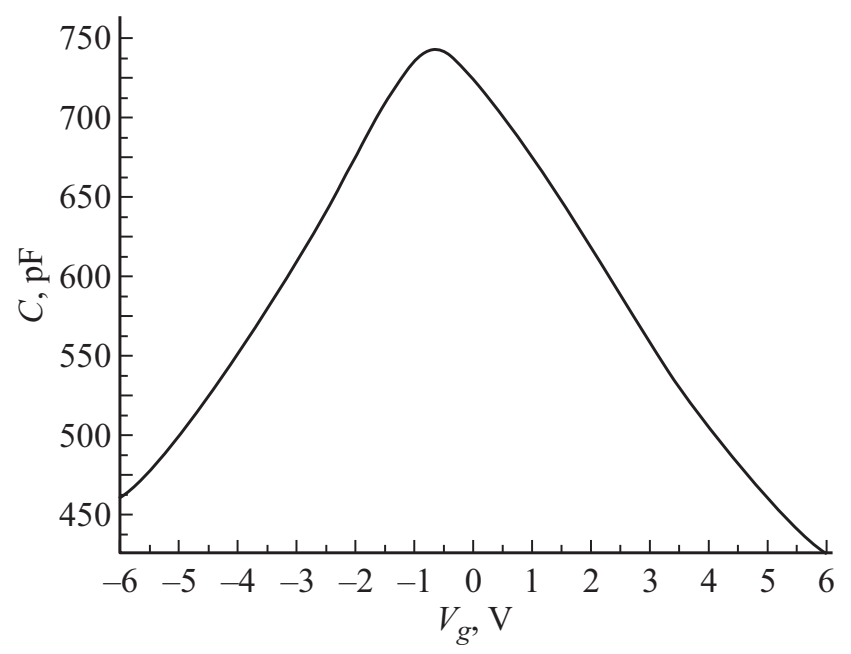

Рис. 2. Высокочастотная вольт-фарадная характеристика структуры $\mathrm{Ni}-\mathrm{Ba}_{0.8} \mathrm{Sr}_{0.2} \mathrm{TiO}_{3}-\mathrm{Pt}$ с толщиной сегнетоэлектрика $120 \mathrm{~nm}$, измеренная при $T=121^{\circ} \mathrm{C}$.

абсолютная температура в энергетических единицах. Величина емкости полупроводника в состоянии flat band вычислялась в работе [6]: $C_{s f b}=9.17 \mathrm{pF}$, результат изложенной процедуры представлен на рис. 3.

Из графика $V_{s}\left(V_{g}\right)$ следует, что по модулю изгиб зон в кремнии многократно меньше приложенного напряжения. В обеднении изменение $v_{s} \mathrm{c} V_{g}$ ограничено сильнее, чем в обогащении, $-5<v_{s}<2$. Малая чувствительность изгиба зон в полупроводнике к изменению $V_{g}$ обусловливает появление плато на полевых зависимостях ВЧ-емкости и проводимости структуры, причем на нижнем, где условие $V_{s} \approx$ const выполняется более жестко, $C$ и $G$ слабее зависят от напряжения, чем на верхнем. 


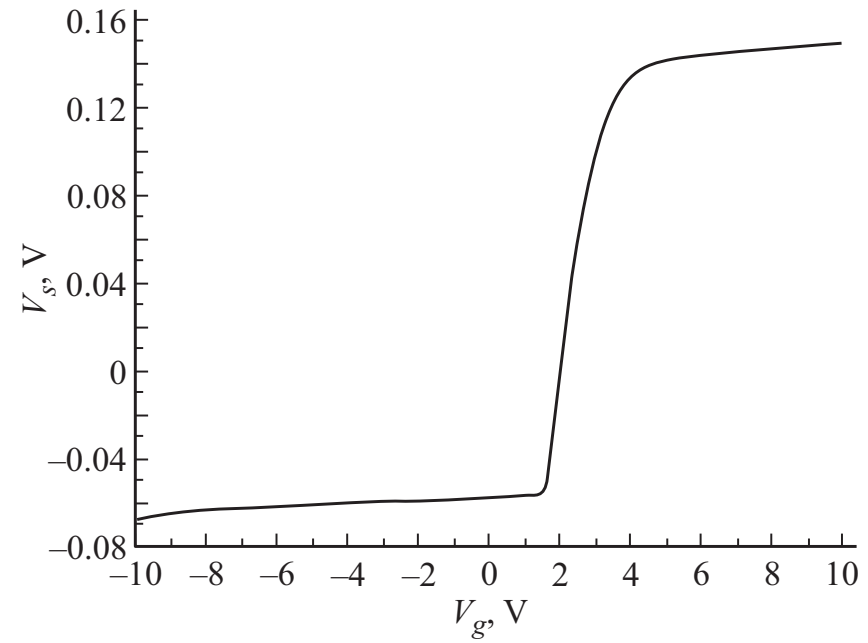

Рис. 3. Зависимость изгиба зон $V_{s}$ в кремнии от внешнего напряжения $V_{g}$ в структуре $\mathrm{Ni}-\mathrm{Ba}_{0.8} \mathrm{Sr}_{0.2} \mathrm{TiO}_{3}-\mathrm{Si}$.

Итак, на образцах с другой толщиной сегнетоэлектрика полностью подтвердились результаты работы [6]: слабое проявление эффекта поля в структурах металлдиэлектрик-полупроводник с сегнетоэлектрическим изолирующим слоем $\mathrm{Ba}_{1-x} \mathrm{Sr}_{x} \mathrm{TiO}_{3}$ обусловлено перезарядкой поверхностных электронных ловушек в межфазном слое. Именно эти локализованные состояния обеспечивают практически полное экранирование поляризации сегнетоэлектрического промежутка в структуре металл-BST-Si. Исходя из размаха изменения внешнего напряжения $(10 \mathrm{~V})$, пользуясь оценкой заряда на ловушках $C_{S E} V_{g}$, получаем, что их концентрация должна быть велика - не меньше $10^{14} \mathrm{~cm}^{-2}$. В рамках настоящей работы рассуждать о природе ловушек можно только из общих соображений. Буферный слой между сегнетоэлектриком и $\mathrm{Si}$ состоит в основном из окисла кремния; поверхностные уровни на границах раздела $\mathrm{Si}_{-} \mathrm{SiO}_{2}$ соответствуют парамагнитным состояниям атомов $\mathrm{Si}$ c неспаренным электроном, связанным с тремя атомами в объеме полупроводника, $\equiv \mathrm{Si}_{3} \mathrm{Si} \bullet-$ так называемыми $P_{b}$-центрами или оборванными связями [11]. Теоретически концентрация этих оборванных связей составляет $8 \cdot 10^{14} \mathrm{~cm}^{-2}$, и они перезаряжаются и при обеднении, и при обогащении полупроводника [11]. Т. е., $P_{b}$-центры вполне подходят для исполнения роли электронных ловушек в образцах металл-BST-Si.

\section{3. Заключение}

Повторим важный тезис из работы [6]: имеет место „аналогия наших современных объектов с сегнетоэлектрическим изолирующим слоем и структур металл- $\mathrm{SiO}_{2}-\mathrm{Si}$ в шестидесятые-семидесятые годы прошлого века, когда активные ловушки на контакте кремния с окислом мешали изготавливать качественные транзисторы с каналом проводимости неосновных но- сителей заряда. Эта проблема была решена технологами за счет пассивации оборванных связей водородом ${ }^{6}$. Поэтому естественно при изготовлении структур металл-BST-Si использовать опыт, накопленный в планарной кремниевой технологии и подавить активность электронных ловушек в межфазном слое. Этот результат позволит создать транзисторы на базе металл-BST-Si c работающим поверхностным каналом неосновных носителей заряда и обеспечит построение высококачественных ячеек энергонезависимой памяти FeRAM.

\section{Финансирование работы}

Работа выполнена в рамках государственного задания и частично поддержана Российским фондом фундаментальных исследований (проекты РФФИ № 18-29-11029, № 19-07-00271 и № 19-29-03042).

\section{Конфликт интересов}

Авторы заявляют, что у них нет конфликта интересов.

\section{Список литературы}

[1] V.R. Mudinepalli, L. Feng, W.-C. Lin, B.S. Murty. J. Adv. Ceram. 4, 46 (2015).

[2] К.А. Воротилов, В.М. Мухортов, А.С. Сигов. Интегрированные сегнетоэлектрические устройства / Под ред. А.С. Сигова. Энергоатомиздат, М. (2011). 175 с.

[3] H. Kawano, K. Morii, Y. Nakayama. J. Appl. Phys. 73, 10, 5141 (1993).

[4] S. Ezhilvalavan, T.Y. Tseung. Rev. Mater. Chem. Phys. 65, 227 (2000).

[5] J.Y. Park, K. Yang, D.H. Lee, S.H. Kim, Y. Lee, P.R. Sekhar Reddy, J.L. Jones, M.H. Park. J. Appl. Phys. 128, 24, 240904 1-24 (2020); doi: 10.1063/5.0035542.

[6] E.I. Goldman, G.V. Chucheva, D.A. Belorusov. Ceram. Int. https://doi.org/10.1016/j.ceramint.2021.04.129

[7] М.С. Иванов, М.С. Афанасьев. ФТТ 51, 7, 1259 (2009).

[8] Д.А. Киселев, М.С. Афанасьев, С.А. Левашов, Г.В. Чучева. ФТТ 57, 6, 1134 (2015).

[9] Е.И. Гольдман, А.Г. Ждан, Г.В. Чучева. ПТЭ 6, 110 (1997).

[10] S.M. Sze, Kwok K. Ng. Physics of Semiconductor Devices. Willey Interscience publication (2007).

[11] В.А. Гриценко. УФН 52, 9, 869 (2009).

Редактор К.В. Емцев 